\title{
Independência ou morte: o grito das Ciências Humanas na luta contra a militância anticientífica
}

○

OPEN ACCESS

EDITADO POR Raquel Freitag (PPGL/UFS)

REVISADO POR Miguel Oliveira Jr.

SOBRE OS AUTORES

Cassiano Santos

Contribuiu com Quezia Oliveira. Papéis: descrição e análise crítica do conteúdo da conferência, parecer crítico da obra, tradução do resumo. revisão do texto.

Quezia Oliveira Contribuiu com Cassiano Santos. Papéis: descrição e análise crítica do conteúdo da conferência, parecer crítico da

obra, tradução do resumo, revisão do texto.

DATAS

Recebido: 06/06/2020 Aceito: 08/06/2020 Publicado: 29/06/2020

COMO CITAR Santos, C.; Oliveira, Q. (2020)

Linguagem e sociedade: Independência ou morte: o grito das Ciências Humanas na luta contra a militância anticientífica. Revista da Abralin, v. 19, n. 2, p. $1-5,2020$.

\section{Cassiano SANTOS (D) \\ Universidade Federal do Rio de Janeiro (UFRJ)}

Quezia OLIVEIRA (D)

Universidade Federal do Rio de Janeiro (UFRJ)

\section{RESUMO}

Nesta resenha crítica da conferência "A guerra contra as Humanidades e o que podem nos ensinar os estudos da linguagem", da professora Dra. Margarida Salomão, abordam-se as principais ideias e consequentes contribuições da fala desta pesquisadora. Dentre os temas observados, estão o negacionismo à ciência, sobretudo na área das Humanidades, e as respostas a este ataque que ciências humanas, em especial os estudos da linguagem, podem dar. A conferencista realiza nesse evento um panorama mundial e brasileiro do cenário político contemporâneo e expõe as relações entre este quadro e a situação atual da ciência. Desse modo, Salomão convoca a audiência a refletir sobre o tema e se engajar nessa luta democrática no espaço acadêmico-científico. Portanto, objetiva-se, com esta resenha, não só referenciar este debate, mas também contribuir para divulgação do saber e desta iniciativa da Abralin ao vivo.

\section{ABSTRACT}

In this critical review of the conference "The war against Humanities and what the studies of language can teach us", by professor Margarida Salomão, the main ideas and consequent contributions of the discussion raised by this researcher in her talk are approached. Among the themes treated in this debate are science negationism, mainly in the field of Humanities, and the responses that human sciences can give, in special the studies of 


\section{REVISTA DA ABRALIN}

language. In this event, the lecturer gives an overview of the world and of Brazil concerning the contemporary political scene; she also exposes the relations between this picture and the present situation of science. Thus, Salomão makes the audience reflect about the theme and engage in this battle for democracy at the scientific and academic area. For this reason, the aim of this review is not only to make reference to this debate but also to contribute to the dissemination of knowledge and of Abralin ao vivo enterprise.

\section{PALAVRAS-CHAVE}

Política. Ciências humanas. Estudos da linguagem. Abralin ao vivo.

\section{KEYWORDS}

Politics. Human sciences. Language studies. Abralin ao vivo.

A conferência "A guerra contra as Humanidades e o que podem nos ensinar os estudos da linguagem" (1:41:34), da professora Emérita da UFJF e deputada federal Dra. Margarida Salomão, faz parte de um evento virtual organizado pela Abralin em colaboração com outras instituições como o CIPL, ALFAL, SAEL e LSA ${ }^{1}$, e transmitido por meio da plataforma de compartilhamento de vídeos Youtube. A transmissão, que foi ao ar às 10h (BRT) do último dia 30/05, contou com a mediação dos professores Dr. Miguel Oliveira Jr. e Dra. Raquel Freitag (UFS), e esteve aberta aos telespectadores para envio de comentários e perguntas por meio do chat disponível na própria plataforma.

A iniciativa da Abralin de promover debates virtuais se dá num momento crucial da história da humanidade, qual seja, o enfrentamento de uma pandemia, que obriga a população a se manter em distanciamento social. Com essa medida, foram necessárias novas maneiras de divulgação do trabalho científico. Assim, o debate científico-acadêmico passa a ganhar novas dimensões, formas de acesso e de interação, o que representa um marco para a comunidade científica do Brasil e do mundo. O evento, que ocorreu de forma gratuita, configura uma maior democratização e disseminação do saber para fora dos muros das Universidades, alcançando um público mais diversificado e abrindo-se ainda mais para um diálogo direto com a sociedade.

A trajetória profissional e política da conferencista tem muito a agregar ao debate do tema. Margarida Salomão, além de professora, foi reitora da UFJF e, sob sua direção, a universidade se lançou numa empreitada democrática de busca de condições mais igualitárias de acesso ao ensino superior pelo sistema de cotas. Também atuou amplamente no setor político como deputada federal desde 2011, tendo sido autora da emenda constitucional 85 que estimula o desenvolvimento científico,

1 Respectivamente: Comité International Permanent des Linguistes; Asociación de Lingüística y Filología de América Latina; Sociedad Argentina de Estudios Lingüísticos e a Linguistic Society of America. 


\section{REVISTA DA ABRALIN}

tecnológico e a inovação. No campo científico, sua carreira acadêmica é marcada por inúmeras contribuições aos estudos linguísticos, especialmente na interface gramática e cognição. Dados esses dois lugares de fala ocupados pela conferencista, a discussão ganha um olhar mais amplo e enriquecedor e desvela mais claramente as conexões entre ciência e política.

A fim de caracterizar a guerra que se trava contra as humanidades na contemporaneidade, a conferencista se vale das contribuições do psicólogo e linguista Steven Pinker $(2011,2019)$. Para ele, esta guerra se caracteriza por um movimento anti-iluminista, em que noções nacionalistas, autoritárias e de militância contra o discurso científico ganham proeminência. O ponto mais grave, observa Margarida Basílio, é que estas convicções anticientíficas se convertem em políticas de governo que impactam ideias antagônicas a elas.

No geral, a ascensão destas políticas se dá por conta de grupos que, na maioria das vezes, perdem seus privilégios devido à democratização (tal como a educacional, por exemplo, no Brasil, em que as políticas de cota restringem o número de vagas para estudantes da elite). Este fenômeno é denominado teoria da fila e foi proposto por Nancy Fraser (2010).

A resposta da ciência a este confronto se torna ainda mais necessária em função das recentes medidas assumidas pelo atual ministério da educação do Brasil que colocam em risco não só a pesquisa acadêmica, mas a própria universidade pública. A exemplo disso, temos a redução dos investimentos na ciência, as intervenções nas agências de fomento à pesquisa, as tentativas de desmontes e desvalorização do trabalho acadêmico, a dissolução de centros culturais e de pesquisa, a propagação de discursos difamatórios contra a universidade, alegando sua falta de produtividade, aplicabilidade ou mesmo relevância em termos de valor de mercado, condensados na famosa acusação de "balburdia" das universidades públicas. Atos como esses ameaçam a universidade pública brasileira e colocam em questão a necessidade de luta por esse espaço e valorização de sua história.

A discussão levantada pela professora nesta conferência traz à tona problemas e inquietações envolvendo a política mundial e o ataque à ciência, em especial nas áreas humanas. Como resposta a essa guerra travada contra as Humanidades, a autora propõe como resoluções contra essa ofensiva os estudos da linguagem, em especial os de semântica cognitiva, de interação humana e de filogênese da linguagem e história humana, sobretudo diante do evento da investigação interdisciplinar e do efeito catraca da abertura da cena pública.

O foco dessa discussão é o cenário científico brasileiro, mas, para isso, a conferencista realiza um movimento de raciocínio mais dedutivo, indo do geral, ou seja, do levantamento sobre o que acontece no mundo em termos político-científicos, para o particular, tratando especificamente da conjuntura brasileira a respeito deste tema. Esse movimento também é feito na desnudação do ataque à ciência. Primeiramente a autora parte do ataque mais geral feito contra a ciência para depois discutir o ataque direto às ciências humanas e sociais, incluindo os estudos da linguagem.

A defesa da pesquisadora é a de que podemos vencer essa guerra e a de que a resposta para isso está justamente no diálogo entre a ciência básica e a pesquisa científica tecnológica. Em outras palavras, é preciso romper com o paradoxo de se investir numa área científica tida de maior importância em detrimento de outra, uma vez que elas se alimentam mutuamente. 


\section{REVISTA DA ABRALIN}

Para ilustrar essa cooperação bilateral, Margarida Basílio cita a contribuição da lógica difusa de Lotfi A. Zadeh (1965). Utilizado na matemática e de cunho inicialmente teórico, trouxe grandes repercussões nas mais diversas tecnologias, como as TICs, a engenharia de controle e a educação, por exemplo. Na linguística, contribuiu para o conceito de semântica escalar em que se percebeu a importância de modalizadores e de intensificadores para a descrição de determinadas categorias semânticas, como altura, por exemplo. Em síntese, estudos pretensiosamente teóricos podem ter desdobramentos imprevisíveis do ponto de vista prático.

A autora cita também, ainda dentro do âmbito dos estudos da linguagem, os trabalhos em semântica de Lakoff (1972) e Fillmore (1982,1998), que asseguraram desenvolvimentos tecnológicos valiosos para a sociedade contemporânea, haja vista as framenets. Ela aponta também como as tecnologias sociais, a exemplo da medida sanitária do isolamento social, contribuíram para as tecnologias bioquímicas no combate à pandemia, ou como a escrita e a invenção da imprensa estiveram associadas diretamente às maiores revoluções tecnológicas e transformações da sociedade, tendo em conta o desenvolvimento da democracia na Grécia, o surgimento do Renascimento com a escrita literária em latim vulgar, a culminação da Revolução francesa a partir da disseminação de ideias pelos livros e enciclopédias etc.

Ponto consensual entre muitos espectadores da conferência, como Luana Amaral (16:05), Lucas Silva (43:48), Sandra Cavalcante (45:31), Thalita Maria (1:16:34) e Paulo Henrique Duque (1:33:00) é a necessidade da divulgação científica e popularização da pesquisa e do conhecimento científico como combate ao negacionismo científico e ao obscurantismo contra as humanidades, o que motivou a pergunta básica da audiência em relação ao debate realizado pela professora Salomão: como realizar essa ampla divulgação? A resposta a esse questionamento parece estar, segundo os espectadores da live, na própria iniciativa do Abralin ao vivo: "Para mim, a própria Abralin ao vivo é uma atividade de divulgação científica espetacular, para além de tudo o mais que essa iniciativa brilhante representa para a comunidade científica da área!" (Gredson Santos-comentário do chat- 1:30:51).

Com essa conferência, a professora Margarida Salomão consegue retratar muito bem os problemas associados ao encolhimento da democracia e da cidadania na sociedade contemporânea. A professora também desnuda os conflitos de interesses políticos por trás dos ataques à ciência e destaca a crucial importância das Humanidades na história do desenvolvimento das sociedades e de suas tecnologias. Com isso, este debate representa, no cenário político brasileiro, um chamamento para a luta democrática, assumindo, assim, nas próprias palavras dos ouvintes, um compromisso científico e político:

Para além do compromisso com a Linguística, Margarida Salomão nos provoca ao compromisso com a Política. Arena ignorada por muitos de nós- linguistas. [...] (Crysna Carmo- Comentário do vídeo).

Abralinaovivo é atividade acadêmica e posicionamento político! [...] (Mariangela Rios Comentário do chat-31:00) 


\section{REVISTA DA ABRALIN}

Por esta razão, o debate promovido aqui é necessário não só para acadêmicos e pesquisadores, mas também para o público em geral, por estar diretamente envolvido nessas questões e sofrer positiva ou negativamente os efeitos da intervenção política na ciência. A exemplo disso, temos visto o caso do Brasil no enfrentamento da pandemia. O discurso encabeçado pelo atual presidente da república de desvalorização da ciência tem colocado parte da população em risco por desconsiderar as recomendações da ciência quanto à necessidade do isolamento social no combate à covid-19. Além disso, minimiza os efeitos da doença, por ignorar os perigos de uso de medicações sem comprovação científica no seu tratamento, ou por não questionar a substituição de dois ministros da saúde em plena pandemia. Como consequência, o Brasil está entre os mais afetados pela doença.

Por fim, cabe destacar que a conferência da professora Salomão consegue envolver a audiência na discussão de um tema crucial em nossa sociedade atual, e, por todos esses motivos, merece ser assistida e divulgada amplamente, para que suas contribuições possam ser desfrutadas por um público cada vez maior.

\section{REFERÊNCIAS}

A guerra contra as Humanidades e o que podem nos ensinar os estudos da linguagem. Conferência apresentada por Maria Margarida Martins Salomão [s.l., s.n], 2020, 1 vídeo (1h 41min 34s). Publicado pelo canal da Associação Brasileira de Linguística. Disponível em: https://www.youtube.com/watch?v=qY6Jt9oqRfw. Acesso em: 30 mai 2020.

FILLMORE, C. J. Frame semantics. In: The linguistic Society of Korea (ed.). Linguistics in the Mornig Calm. Seoul: Hanshin, p. 111$138,1982$.

FILLMORE, C. J.; ATKINS, B. T. S. FrameNet and lexicographic relevance. In: Proceedings of the First International Conference On Language Resources And Evalutation. Granada, p. 417-423, 1998.

LAKOFF, G. Hedges: a study in the meaning criteria and the logic of fuzzy concepts. CLS - 8. Chicago, 1972.

FRASER, N. Injustice at Intersecting Scales: On 'Social Exclusion' and the 'Global Poor'. European Journal of Social Theory 13, (3), p. 363-371, 2010.

PINKER, S. The better angels of our nature. New York, NY: Viking, 2011.

PINKER, S. Why we are not living in a Post-truth era: an (unnecessary) defense of reason and a (necessary) defense of universities' role in advancing it. Skeptic, Altadena (CA), 24 (3), 2019.

ZADEH, L. Fuzzy sets. Information and Control, 8(3), p. 338-353, 1965. 